\title{
A pedagogia da linguagem na ação evangelizadora cristã no processo do discipulado
}

\author{
The pedagogy of language in christian evangelizing action \\ in the discipulate process
}

Alcione Carvalho da Silva ${ }^{\mathbf{1}}$

\section{Resumo}

O artigo aborda a evangelização da igreja católica e os ritos de iniciação à vida cristã. Atualmente, emergem problemas e desafios para a fé, tais como o seguimento cristão; a manutenção do vínculo relacional de pertença à comunidade enquanto garantia de seguimento e prática dos sacramentos iniciais. O estudo centra-se em pesquisa sobre documentos da igreja católica em contexto social e religioso. Analisase a linguagem e as implicações para a ação do discípulo, o seguimento e vivência em uma perspectiva pedagógica e pastoral. Explicitam-se conceitos fundamentais como fé, comunidade, seguimento, anúncio e discipulado. Reflete-se numa ótica teológico-pastoral, a fim de enfrentarmos as novas linguagens e tendências atuais, numa perspectiva de esperança como força contínua na prática discipular.

Palavras-chave: Evangelização; linguagem; discipulado; pedagogia; prática.

\begin{abstract}
The article addresses the evangelization of the Catholic Church and the rites of initiation into the Christian life. Today, problems and challenges for the faith are emerging, such as Christian follow-up; the maintenance of the relational bond of belonging to the community as a guarantee of follow-up and practice of the initial sacraments. The study focuses on research on documents of the Catholic Church in a social and religious context. The language and implications for the disciple's action are analyzed, as well as the follow-up and experience in a pedagogical and pastoral perspective. Fundamental concepts such as faith, community, follow-up, announcement and discipleship are explained. It is reflected in a theological-

\footnotetext{
${ }_{1}$ Doutorando em Teologia Sistemática pela Pontifícia Universidade Católica do Rio Grande do Sul (PUCRS). O presente trabalho foi realizado com apoio do Programa de Suporte à Pós-Graduação Coordenação de Aperfeiçoamento de Pessoal de Nível Superior - Brasil (CAPES).

E-mail: nonesilva976@gmail.com
} 
pastoral perspective, in order to face the new languages and current trends, in a perspective of hope as a continuous force in discipleship practice.

Keywords: Evangelization; language; discipleship; pedagogy; practice.

\section{Introdução}

A presente pesquisa bibliográfica quer apontar caminhos para uma experiência pastoral renovada, incluindo questões reflexivas sobre linguagem e discipulado. Conhecedores da situação social, mudanças antropológicas que envolvem a atualidade, somos chamados a reavaliar a forma ou a pedagogia que estamos usando na formação e conhecimento de nossa fé e como instigarmos famílias, jovens e crianças a vivenciarem em comunidade cristã aquilo que os sacramentos suscitam como frutos de uma evangelização coerente.

Desse modo, propomos uma reflexão teológica pastoral embasada no espírito do seguimento cristão na modernidade, que vem sofrendo as consequências das grandes transformações ocorridas neste século, como o individualismo, hedonismo, cultura midiática e virtual, bem como o sincretismo religioso e globalização. Essas mudanças já foram ressaltadas como "mudança de época e novos desafios para catequese" ${ }^{2}$. Queremos dar ênfase ao empenho que a Igreja vem realizando a fim de saber conduzir todas essas inovações, segundo o espírito cristão que quer ver nossas atitudes reais, diante dos quadros sociais que vivemos hoje, como injustiça e falta de entrosamento e envolvimento entre os membros da comunidade.

Diante dessas considerações, refletimos sobre como enfrentar o problema da linguagem na transmissão da fé e sua exigência intrínseca de vida comunitária e testemunho social num contexto de crise e fragmentação.

Para elaborarmos esta pesquisa, usamos alguns documentos da Igreja Católica, dados eletrônicos de diferentes sites, obras bibliográficas e o $\operatorname{artigo~}^{3}$ publicado na Revista Eclesiástica Brasileira do professor Dr. Fr. Susin4, que foi para nós a fonte inspiradora para realização desta pesquisa.

2 COMISSÃO EPISCOPAL PASTORAL PARA A ANIMAÇÃO BÍBLICO-CATEQUÉTICO, Itinerário
Catequético. Iniciação à vida cristã - um processo de inspiração catecumenal, 2017, p.25 a 33.
3 SUSIN Luiz Carlos, O "calcanhar de Aquiles" da iniciação à vida cristã. In: Revista Eclesiástica
Brasileira (REB), vol. 79, n. 312 (Jan./Abr.) 2019, p.34-59.
4 Professor na PUCRS desde 1975, com algumas licenças para estudos e docência em Roma e um pós-
doutorado em Washington. Seu doutorado com o pensamento de E. Lévinas significou uma interface
entre Filosofia e Teologia, através da Antropologia, com o método fenomenológico. Mais tarde, outro
autor, René Girard, com quem realizou seminário. Atualmente, tem o encargo de Secretário Geral
do Fórum Mundial de Teologia e Libertação, ligado ao Fórum Social Mundial, e membro do Comitê Opinião Filosófica - ISSN: 2178-1176 - Editora Fundação Fênix. www.fundarfenix.com.br 
Desse modo, o trabalho desenvolve-se em três itens. O primeiro situa-nos dentro do contexto social de modo a tomarmos consciência sobre algumas das situações sociais e como a Igreja aponta saídas diante das crises de fé e vivências. Para o segundo item, seguimos com uma revisitação nos ideais cristãos e uma breve hermenêutica bíblica e dos ensinamentos que a Igreja traz, seguindo os ensinamentos do magistério e da tradição. Já o terceiro item procura trazer algumas respostas aos questionamentos levantados no decorrer do trabalho, focalizando no dom da esperança como aliada para vencer os desafios que o tempo impõe-nos.

\section{Reprimenda Preliminar}

A Igreja no Brasil vem, de modo especial, nestes últimos anos, indagando-se sobre o método como a formação catequética vem acontecendo em nossas comunidades de fé. Dentro dessa temática, já tivemos contato com vários documentos 5 , artigos, estudos, planos que focalizam e procuram dinamizar este tema. Percebemos que é um tema difícil de ser desenvolvido na vida prática, pois a linguagem cristã vem enfrentando barreiras para tornar-se uma prática que realmente atinja com profundo entusiasmo e força evangélica transformadora no cotidiano das novas gerações, onde assumir a fé e anunciar tornou-se algo problemático e desafiador.

A pedagogia é uma ciência que se justifica em tratar-se da educação e formação das crianças e jovens com métodos em que possa ocorrer a adaptação recíproca de cada indivíduo na construção de seu conhecimento e, assim, podemos utiliza-la de modo adequado para colhermos frutos dentro da área da evangelização e conhecimento da igreja que traz em si o conhecimento Bíblico, a Sagrada Tradição e o Magistério.

Com o advento da modernidade, percebe-se que tudo passa por uma reavaliação e atualização no tempo presente. É questionado e posto à prova tudo o que se relaciona com usos, costumes, valores e tradições vividas pela humanidade que, no decorrer deste artigo, não iremos polemizar, pois, assim, iríamos além do

Científico da Revista Internacional de Teologia CONCILIUM. Membro da Equipe de Reflexão Teológica da Conferência dos Religiosos do Brasil. Frade capuchinho.

5 Documentos lançados pela CNBB, como o Catequese Renovada em 1983; Diretório Nacional de Catequese; Itinerário Catequético, Iniciação à vida cristã - um processo de inspiração catecumenal Cf: https://soucatequista.com.br/documentos-sobre-a-catequese-da-igreja-no-brasil.html 
seu eixo central, no entanto, precisamos nos conscientizar que toda essa reviravolta científica, tecnológica, social, hermenêutica e linguística, entre outros aspectos, afeta a missão evangelizadora.

\title{
Expondo uma problemática paradoxal moderna
}

A Igreja sempre foi um lugar de anúncio, de usar a linguagem como testemunho e epistemologicamente trazer presente o conhecimento sobre Deus, segundo uma tradição e caminhando em conformidade com o magistério católico. Podemos comprovar toda essa pedagogia ao visitarmos filósofos, teólogos, os santos padres e tudo o que se definiu até o momento no decorrer dos concílios que foram vários no decorrer da história da Igreja. Na obra Dogma e Anúncio, de Ratzinger, somos levados a refletir sobre como tudo hoje está sendo anunciado e vivenciado pela Igreja. Assim sendo, afirma-nos:

\begin{abstract}
Com efeito, parece-me que se pode encontrar uma resposta melhor do que a de uma teologia da comunidade tão desesperada como a que acabamos de conhecer, justamente se considerarmos mais exata e cuidadosamente do que se dá em tais afirmações a realidade de 'comunidade' ao redor da qual aqui tudo gira; não há dúvida de que então também devemos estar prontos a aceitar a complicação da realidade, que não pode ser captada em fórmulas baratas. Uma comunidade só será comunidade da Igreja, uma grandeza de relevância superior a uma grandeza de relevância superior a um associacionismo particular, se não for autônoma, fechada em si. [...]. Mas só na medida em que na mudança dos experimentos intelectuais e na oposição das opiniões individuais é portadora da permanência e lugar do que é comum, na medida em que atua na força do Espírito Santo, o qual, sem dúvida, nisto se serve de suposições absolutamente naturais do comportamento humano ${ }^{6}$.
\end{abstract}

Dessa forma, o trabalho que ora apresentamos, com a temática a pedagogia da linguagem na ação evangelizadora cristã no processo do discipulado, visa a instigar-nos a ampliarmos nosso olhar e método na formação da fé das crianças e jovens, bem como das famílias constituídas sob a influência da era moderna e seus dinamismos. Mas não iremos descrevê-los detalhadamente no momento. Deixamos como sugestão para o leitor aprofundar o tema visitando obras que o relatam, documentos do Concílio Vaticano II, de modo especial a Lumem Gentium; Gaudium et Spes, Ad Gentes, Dignitatis humanae e as exortações do nosso atual Papa Francisco, como a Evangelii Gaudium, pois é um modo de nos recolocarmos

${ }^{6}$ RATZINGER, Joseph, Dogma e anúncio, p. 35.

Opinião Filosófica - ISSN: 2178-1176 - Editora Fundação Fênix. www.fundarfenix.com.br 
inseridos nessa temática e agirmos concretamente para nos atualizar e avaliar nossa ação cristã.

Para isso, somos chamados a ter diante de nosso olhar a imagem das primeiras comunidades cristãs, para que, assim, a Igreja possa sempre voltar-se ao essencial que é a prática comunitária, a qual vai além do puro formalismo doutrinário e busca dos sacramentos em si, sem a responsabilização a priori que se envolve, como a prática da justiça, local da caridade, do cuidado, da dignidade. Lógico que tudo isso se vê ao estudarmos a doutrina cristã, mas nossa linguagem precisa fazer que seja demonstrado na ação concreta, nas experiências observadas em nossa sociedade.

Hoje vivemos uma realidade em nossas comunidades que trazem a essência cristã, ou seja, estar reunidos em torno da fé, da vivência e práticas sociais, muito esfaceladas entre os membros dessa mesma comunidade. Destacamos a imagem do surgimento das primeiras comunidades cristãs relatadas em Atos dos Apóstolos (Cf: At4,32), “A multidão dos fiéis tinha uma só alma e um só coração". Hermeneuticamente, percebemos que, na origem, a unidade era algo real, intenso, que formava esta igreja nascente. Não podemos generalizar e afirmar que hoje não há mais verdadeiras comunidades, que não há unidade entre os cristãos, pelo contrário, se não houvesse, teríamos de ter excluído do vocabulário atual a palavra "Igreja", temos, sim, de reconhecer que somos membros do corpo de Cristo, que hoje continua se manifestando na sua forma de ser Igreja, embora, como já salientamos, de modo que diverge da imagem original. Precisamos entender que: "Por igreja queremos dizer tanto o corpo local quanto o universal de Cristo. Ela serve como antidoto tanto contra o individualismo quanto contra o tribalismo" 7 . A Igreja é um local privilegiado, onde podemos ouvir a Palavra de Deus, a qual é atualizada aos nossos tempos, os ensinamentos cristãos e exercitar na prática o que a Palavra move-nos conforme Cristo revelou-nos.

A realidade em que estamos inseridos, em que a Igreja está sendo chamada a dar testemunho e cultivar a fé, é uma realidade nova, com desafios novos, porque não só aconteceram mudanças na rotina diária do ser humano, como no modo de pensar e de estabelecer relações entre nós nessa época. Isso afeta desde o conhecimento e a busca sobre Deus, como no modo de cuidarmos da comunidade e

\footnotetext{
7 KLEIN, Willian W. BLOMBERG, Craig L. HUBBARD, Robert Jr., Introdução à interpretação bíblica, p. 256 
como vemos nossos semelhantes, principalmente diante dos desafios da fome, miséria, saúde, desemprego entre outras realidades também desafiadoras como o sincretismo religioso, individualismo, globalização, liquidez, virtualismo, cultura midiática. Algo que nos preocupa, fruto da tecnologia talvez, é a relação virtual que vem ganhando espaço e destruindo com as verdadeiras relações, segundo os moldes antropológicos cristãos. Outro ponto que segue forte dentro da realidade atual é o hedonismo, que já foi destacado pelo episcopado brasileiro, pois

o corpo, a saúde, a beleza, a riqueza, o sexo, são assumidos como valores absolutos que orientam as opções e os comportamentos cotidianos [...], torna cada pessoa a norma de si mesma, numa busca de deleite absoluto que não leva em consideração o fato de que a vida prazerosa é fruto de uma com quista, de fadiga de reciproca renúncia e colaboração ${ }^{8}$.

Além disso, um dado significativo que devemos considerar é, ao olharmos os dados do IBGE na coleta de dados sobre as religiões, vermos que se dizem católicos 64,63\% da população brasileira; 22,16\% afirmam-se evangélicos e, em terceiro lugar, estão aqueles que se dizem ser sem religião, ou seja, 8,04\% e as demais religiões giram de 0,01\% a 2,02\%9. Percebe-se que a religião católica ainda é uma das principais, porém, vem, no decorrer das décadas, decaindo. O que nos preocupa é o aumento da percentagem de evangélicos e outras denominações. Diz-se que ocorre uma circulação de fiéis entre diversas igrejas que surgem hoje com várias denominações e com modos diferenciados de viver o "pentecostalismo". Essa circulação entre Igrejas dir-se-á porque os indivíduos buscam maior autonomia que faz objetar na desinstitucionalização e descomprometimento social, ditames morais, busca por autoajuda, empreendedorismo, demanda material, afetiva e subjetiva. Toda essa mudança religiosa convoca-nos olharmos a linguagem que estamos usando, bem como a transmissão teológica e vivencial que se está construindo, pois devemos continuar pedagogicamente ensinando o que Cristo nos ensina e rever a questão do comprometimento e vivência comunitária motivada pela vivência sacramental.

${ }^{8}$ COMISSÃO EPISCOPAL PASTORAL PARA A ANIMAÇÃO BÍBLICO-CATEQUÉTICO, Itinerário Catequético. Iniciação à vida cristã - um processo de inspiração catecumenal, p.27

${ }^{9}$ (Cf: https://journals.openedition.org/confins/7785?lang=pt). 


\section{O mandato de Cristo e o sentido da igreja na atualidade}

Observando os dados científicos comprovados e citados anteriormente, devemos considerar o versículo que diz: "Portanto, ide fazer discípulos entre todos os povos, batizai-os consagrando-os ao Pai, ao Filho e ao Espírito Santo, e ensinailhes a cumprir tudo o que vos mandei. Eu estarei convosco sempre até o fim do mundo" (Mt28, 19-20). Nesses breves versículos, encontramos Mateus nos revelando, na figura de linguagem hipocatástase, uma profunda Cristologia e grandeza eclesiológica, uma missão universal, realizando um rito de consagração sob o olhar da Trindade, ou seja, o sacramento do Batismo. Já fica claro que o fruto consequente deste será uma vida construída sob as "insígnias" de Cristo.

Identificamos, neste caso, Cristo falando do batismo como fonte iniciática da caminhada. A Igreja na tradição define três sacramentos como iniciantes à vida cristã: batismo, crisma e eucaristia. Tradicionalmente, ocorre o batismo, ainda logo ao nascimento da criança; a eucaristia no início da adolescência e a crisma como confirmação de uma vida já adulta, por volta da idade de 14 anos, marcando o início da juventude. Cada sacramento segue sua ritualidade própria como nos ensina o magistério. Desse modo, devemos refletir como tudo isto está sendo realizado em nossas comunidades de fé, pois se não tivermos uma linguagem adequada aos tempos modernos, se não exercitarmos o engajamento comunitário, responsabilidades sociais e o que reflete ser cristão, todos os sacramentos passam a ser na vida de nossas comunidades, que ora ainda chamamos, de simples ritos de passagens ${ }^{10}$. Talvez intrinsecamente com uma profunda pobreza significativa,

${ }^{10}$ Tomamos aqui, uma interpretação de Girard que diz: A tragédia grega situa-se, pois, em um período de transição entre uma ordem religiosa arcaica e a ordem mais "moderna", estatal e judiciária, que vai sucedê-la. Leitura trágica do mito e reprodução dessacralizada do rito, a tragédia manifesta sua origem religiosa. Todo o problema concentra então em torno do religioso primitivo, que se exprime objetivamente nos mitos e nos ritos, e cuja "gênese, função e estrutura" devem ser procuradas. Devem ser procuradas porque a intuição de Girard não tem precedentes nem modelos a seguir: "Não temos nem guia nem modelo; não participamos de nenhuma atividade definível. Não nos podemos reclamar de nenhuma disciplina reconhecida. O que queremos fazer é tão estranho à tragédia ou à crítica literária quanto à etnologia ou à psicanálise". Há uma origem real que os mitos, a seu modo, não cessam de rememorar, e os ritos, a seu modo, não cessam de comemorar. Deve tratar-se de um acontecimento que exerceu sobre os homens uma impressão, não indelével, posto que eles acabam por esquecê-lo, mas de qualquer modo muito forte. Essa impressão se perpetua por intermédio do religioso e de todas as formas culturais. Não é, pois, necessário, para disso se dar conta, postular uma forma qualquer de inconsciente, seja individual, seja coletivo (Cf: https://www.scielo.br/scielo.php?script=sci arttext\&pid=S0101-31731974000100014).

Observamos nesta interpretação, que estamos mais do que nunca, vivendo este tipo de mudança, porque muitas coisas deixam de ser significativas na vida de cada um e consequentemente substituídas por outras, atribuindo-lhe valor, deste modo, analisemos a forma como acontece a iniciação a vida cristã, inspirados por este prisma interpretado de Rene Girard. 
ficando muito abaixo, no sentido de valor cristão, dos ritos realizados por diferentes povos e culturas (indígenas, nômades e outros). Embora vivamos cercados de rituais de passagem que marcam o início ou fim de etapas, conquistas para justificar que vivemos em processos de mudanças em nossas histórias individuais e civil (ex. $1^{0}$ emprego, nascer de um filho, perda de um ente entre outros). Religiosamente, é obvio que os ritos sacramentais transcendem nossa realidade e colocam-nos na dimensão do sagrado, do divino, visto que são ritos que nos levam a uma maior intimidade com Deus.

Hoje vemos um paradoxo entre o que realmente é uma vida comunitária e o que se define por sociedade. Em um artigo escrito por Luiz Carlos Susin intitulado como "O 'calcanhar de Aquiles' da iniciação à vida cristã", o autor procura examinar como acontece a iniciação cristã dentro de uma sociedade secularizada e que vive um pluralismo religioso, focalizando na diferenciação entre comunidade e sociedade. ${ }^{11} \mathrm{~A}$ linguagem teológica e a pedagogia hoje deverão fazer ocorrer a "unidade entre a pertença à comunidade católica e a presença responsável e atuante como cristão e cidadão adulto na sociedade. E a necessidade de uma iniciação única que costure bem esta polaridade entre comunidade e sociedade". ${ }^{12}$ Sob a instigação deste referido artigo e levando em consideração o que a Igreja brasileira está vivenciando, realmente se percebe a necessidade dessa busca e retorno "às fontes cristãs", mas capacitando evangelizadores que, além de uma linguagem adequada para a modernidade, consigam fazer um elo forte para o enfrentamento das situações já salientadas, de modo essencial a fé vivida e inserida dentro de uma comunidade com um novo $\operatorname{ardor}^{13}$, por isso, Susin destaca que:

O documento 100 da CNBB clama por um esforço absolutamente necessário, e há bons subsídios. E mesmo assim, de lá para cá, algo estrutural parece faltar na prática da iniciação cristã, o 'buraco' que engole os esforços de centenas ou milhares de catequistas que se propõem a ser formadores da fé e mestres da iniciação cristã: as exigências de ordem antropológica de todo processo de iniciação, a implicância do 'rito de

\footnotetext{
${ }^{11}$ SUSIN Luiz Carlos, O "calcanhar de Aquiles" da iniciação à vida cristã, p35-38.

${ }^{12}$ SUSIN Luiz Carlos, O "calcanhar de Aquiles" da iniciação à vida cristã, p37.

${ }_{13}$ Quando falamos de ardor, queremos salientar que se deve seguir vencendo os obstáculos do indiferentismo e da injustiça, pois essa deve ser sempre, aliado aos ensinamentos da Palavra de Deus, uma das metas a serem realizadas pela Igreja junto ao povo como salienta a documento de Aparecida no número 248 a 257 (Cf: CONSELHO EPISCOPAL LATINO-AMERICANO, Documento de Aparecida. Texto Conclusivo da V Conferência Geral do Episcopado Latino-Americano e do Caribe. São Paulo: Paulus, 2007, p. 116 a 120), que propõe entre outros, que saibamos fazer uma autentica conversão, comunhão e solidariedade. Os desafios pastorais hoje se passa, também por sabermos usar uma linguagem adequada, são de muitos modos que inspirados em Cristo, possamos agir junto as situações mais frágeis que surgem no campo da evangelização.
} 
passagem' de forma atualizada e realista, suas etapas e, sobretudo, suas provas e treinos em situações sociais marginais ${ }^{14}$

Neste recorte, queremos, mais uma vez, salientar o quão instigante o tema que estamos abordando é desafiador. Os tempos são outros. Susin convoca-nos a avaliarmos "nossa época de hegemonia da tecnociência, do mercado e do consumo, vive uma orfandade de simbolização e de ritualização da condição humana, e isso não é sem consequências graves" ${ }^{15}$, e com certeza, já estamos arcando com as consequências de tudo isso. Talvez por termos negligenciado, lá no renascimento, um maior cuidado com o futuro da formação religiosa.

Na obra “O Deus escondido da pós-modernidade", onde o autor procura trazer presente alguns dados da teologia de Karl Barth e de Paul Tillich, ou seja, um autor com linguagem voltada ao dogmático e outro ao sistemático, ambos refletindo pontos do pensamento de René Girard, leva-nos a refletir sobre como falar de Deus em tempos modernos. Aqui podemos justificar o que já exprimimos, quando se diz que:

Pois bem, o retorno do religioso se apresenta com frequência sob a forma de renascimento da religião segundo formas emocionais, como estranha combinação de confissão da fé e afirmação narcisista típica de um sujeito ameaçado. [...]. Nesse sentido, o termo religião não é sinônimo de espiritual, mas muito pelo contrário, representa com frequência seu abafamento, seu disfarce ou, ao menos, seu mascaramento segundo o páthos do sentimento aloucado, da emoção irracional e da certeza de uma suposta manifestação divina no meio da banalidade do cotidiano, experiência que o faz explodir para além de seus próprios limites ${ }^{16}$.

Seguindo ainda um pouco do autor citado, ele relata-nos que a nossa fé deveria sempre iluminar nossa existência ao ponto de sabermos detectar o início do subjetivismo para podermos vencê-lo. Isso é possível porque, quando conseguirmos identificar e despertar dele, conseguiremos fazer uma potente experiência do que seja fides como doação e encontro, concretizando a promessa de tempos novos, como escreve São Paulo em algumas de suas cartas. Observamos:

E isso segundo o que Cristo revelou: não um desejo de apropriação, mas
um de doação que visa a estabelecer a Koinonía. À luz de tal
acontecimento, é possível habitar o mundo de outra maneira: na exposiçãao
da finitude, segundo a lógica não totalitária da gratuidade. No coração
dessa profundidade de experiência, será possível afirmar que os verdugos
já não triunfam sem ser ingênuos, na medida em que a vítima é a única

${ }_{14}$ SUSIN Luiz Carlos, O "calcanhar de Aquiles" da iniciação à vida cristã, p38.

${ }_{15}$ SUSIN Luiz Carlos, O "calcanhar de Aquiles" da iniciação à vida cristã, p42.

16 ALVAREZ, Carlos Mendoza. O Deus escondido da pós-modernidade. Desejo, memória e imaginação escatológica. Ensaio de teologia fundamental pós-moderna, p.32. 
capaz de exercer a potência de conduzi-lo para além da rivalidade e do ressentimento ${ }^{17}$.

Notamos que é uma reviravolta tremenda que nossa linguagem e atitudes catequéticas têm de realizar, pois hoje é fazermos uma caminhada indo contra um modo de vida que já se instaurou sobre a terra. Ser iniciado no processo do discipulado sempre foi uma tarefa, e atualmente, mais árdua se realmente quisermos seguir o cristianismo segundo as suas raízes. Fé é algo que precisamos trazer em pauta devido aos maus entendimentos que vemos hoje, onde é confundido com o puro bem-estar pessoal. Ratzinger afirma que:

[...] na fé cristã vive do fato de não apenas haver um sentido objetivo, mas esse sentido me conhecer e amar, de eu poder me confiar a ele com a atitude da criança que se sabe acolhido com todas as suas perguntas no tu da mãe. Dessa maneira, a fé, a confiança e o amor são, em última análise, uma coisa só, e todos os conteúdos que a fé envolve são nada mais que a concretizações daquela reviravolta que forma a base de tudo, ou seja, do 'Creio em ti', da descoberta de Deus na face do homem de Nazaré18.

Desse modo, podemos ter claro que fé, confiança, amor formam um único conteúdo, que nos leva a descobrir Deus na face de Jesus Cristo e do outro que está ao nosso lado.

\section{O despertar das luzes}

Quando contemplamos Cristo, somos conduzidos ao evento "cruz". Assim, seguindo o pensamento cristão, as reflexões que até hoje a teologia propõe-nos sobre a cruz, vemos nela um florescer de esperança. Os desafios estão aí, mas não podemos perder a esperança (uma das virtudes teologais), e seguirmos, no momento atual, descobrindo formas, linguagens e gestos que mostram concretamente a evangelização transformando a vida do ser humano. Bento XVI, na carta encíclica sobre a esperança cristã, no ano de 2007, assinalava:

A verdadeira e grande esperança do homem, que resiste apesar de todas as desilusões, só pode ser Deus - o Deus que nos amou e ama ainda agora até o fim, até a plena consumação (Jo13,1 e 19,30). Quem é atingido pelo amor começa a intuir em que consistiria propriamente a vida. Começa a intuir o significado da palavra esperança que encontramos no rito do Batismo ${ }^{19}$.

\footnotetext{
17 ALVAREZ, Carlos Mendoza. O Deus escondido da pós-modernidade. Desejo, memória e imaginação escatológica. Ensaio de teologia fundamental pós-moderna, p.291.

${ }^{18}$ RATZINGER, Joseph. Introdução ao Cristianismo. Preleções sobre o Símbolo Apostólico, p.59

19 BENTO XVI. Carta Encíclica Spe salvi. Sobre a Esperança Cristã, n.27
} 
A esperança é sempre essa luz no fim do túnel que nos chama, orienta. Ao mesmo tempo em que os desafios do tempo presente parecem derrotar-nos ou entristecer-nos, somos chamados a anunciar Cristo com alegria e o mais pleno possível, imbuídos do Espírito de Cristo. O Papa Francisco assinala:

\begin{abstract}
[...]. Algumas pessoas não se dedicam à missão, porque creem que nada pode mudar e assim, segundo elas é inútil esforçar-se. Pensam 'para quê privar-me das minhas comodidades e prazeres, se não vejo algum resultado importante? ' Com esta mentalidade, torna-se impossível ser missionário. Esta atitude é precisamente uma desculpa maligna para continuar fechado na própria comodidade, na preguiça, na tristeza insatisfeita, no vazio egoísta. Trata-se de uma atitude autodestrutiva, porque 'o homem não pode viver sem esperança: a sua vida, condenada à insignificância, tornar-se-ia insuportável'2o
\end{abstract}

É uma linguagem assim, como nos dirige Papa Francisco, que nos entusiasma, determina a ir adiante e saber que a humanidade não está perdida, porque, hoje, Cristo está ressuscitado e conta com nossa ação concreta, fé, esperança e alegria em anunciá-lo. Para Álvarez, chegamos a um momento crucial para expor o pensamento cristão. Se em Francisco percebemos um otimismo e esperança, o autor chama-nos a contemplar a fides cristã e cita uma reflexão de Descartes que relata como se encontra fragilizado o sentimento de esperança no coração do homem: "A esperança é uma disposição da alma a se persuadir de que o que ela deseja advirá [...] E o temor é outra disposição da alma, que a persuade de que ele não advirá" ${ }^{21}$. Em outra passagem, Álvarez salienta as virtudes teologais como ainda sendo uma fonte de dinamismo, destacando a esperança como a virtude do porvir e, assim, traz um breve poema de Charles Péguy, “A pequena esperança caminha no meio de suas duas irmãs mais velhas e não é levada muito a sério... É ela, aquela pequena, quem leva tudo. A caridade não ama senão aquilo que é, e ama o que será”22.

Sendo assim, tenhamos essa grande esperança no futuro da evangelização e façamos junto com a Igreja cristã um verdadeiro processo pedagógico e linguístico para concretizarmos um discipulado capaz de transformar o que nos vem hoje, na realidade, como sombras, perdições em sinais de luzes e de encontro com Cristo

\footnotetext{
${ }^{20}$ PAPA FRANCISCO. Exortação apostólica Evangelii Gaudium. A Alegria do Evangelho, n.275

${ }^{21}$ ALVAREZ, Carlos Mendoza. O Deus escondido da pós-modernidade. Desejo, memória e imaginação escatológica. Ensaio de teologia fundamental pós-moderna, p.193

${ }^{22}$ Op. Cit. p.193

Opinião Filosófica - ISSN: 2178-1176 - Editora Fundação Fênix. www.fundarfenix.com.br
} 
conosco para podermos construir a verdadeira comunidade cristã aos moldes do início do Cristianismo.

\section{Conclusão}

Ao fazermos a leitura deste artigo, somos instigados a fazermos reflexões sobre alguns pontos abordados por ele, pois são hoje, de importância relevante, principalmente quando queremos colocar em prática nossos conhecimentos teológicos e o nosso envolvimento cristão.

Vimos que a linguagem, hermenêutica e a pedagogia que utilizamos até hoje, precisam ser reformuladas em alguns aspectos, principalmente no que trata de fé e ação, espiritualidade e vivência. Não queremos sair do essencial ou ir contra uma tradição, mas, pelo contrário, precisamos resgatar o que se perdeu, talvez, no decorrer da história. Precisamos utilizar uma linguagem envolvente, que penetre no coração da humanidade, fazendo com que ela perceba as influências negativas que os tempos modernos trazem em alguns aspectos, como no testemunho de fé, comprometimento e responsabilidades sociais e comunitárias. Um momento propício para isso acontecer é o momento da formação religiosa passado para as novas gerações.

E, assim, analisando algumas obras e textos de autores e da própria Igreja que demonstram suas preocupações e dão pistas para agirmos como verdadeiros cristãos, somos convocados a assumir realmente estas mensagens e ensinamentos. Como nos diz Paul Ricoeur:

\footnotetext{
O mundo do texto de que falamos não é, portanto, o da linguagem quotidiana; neste sentido, ele constitui uma nova espécie de distanciação que poderia dizer-se do real consigo mesmo. É a distanciação que a ficção introduz na nossa apreensão da realidade. Já dissemos que uma narração, um conto, um poema não existe sem referente. Mas este referente está em ruptura com o da linguagem quotidiana; pela ficção, pela poesia, abremse novas possibilidades de ser-no-mundo, na realidade quotidiana; ficção e poesia visam o ser, já não sob a modalidade do ser-dado, mas sob a modalidade do poder-ser. Por isso mesmo, a realidade quotidiana é metamorfoseada graças ao que poderíamos chamar as variações imaginativas que a literatura opera no real 23
}

23 RICOEUR, Paul. Do texto a ação. Ensaios de hermenêutica II. p.122 . 
Desse modo, que possamos realmente tomar posse dos textos, da Palavra de Deus e tudo o que realmente nos faz mais humanos no sentido antropológico do ser, que hoje somos tentados a distanciar-nos e ficarmos sem um referente.

Precisamos formar no coração dos evangelizadores uma consciência ampla, que saibam olhar para as realidades presentes e pedagogicamente, levar as novas gerações a sentirem-se envolvidas pelos ensinamentos e missão cristã, a sairmos da "mesmice" e realmente aprendermos a lidar com o real, no qual estamos inseridos, de forma atualizada, sem perder os valores éticos, morais e cristãos.

Que esta leitura, que não teve a pretensão de esgotar a temática proposta, mas apenas dar pistas e instigar-nos a irmos adiante em nossas pesquisas e análises, faça continuarmos com a esperança em dias melhores, em vermos uma humanidade transformada na linguagem do amor que Cristo desenvolve e revela-nos.

\section{Referências}

ALMEIDA, Ronaldo de. O que significa o crescimento evangélico no Brasil? Le Monde Brasil Diplomatique. 52. ed. Disponível em: $<$ https://diplomatique.org.br/o-que-significa-o-crescimento-evangelico-nobrasil/> Acesso em 03/07/2020.

ALVAREZ, Carlos Mendoza. O Deus escondido da pós-modernidade. Desejo, memória e imaginação escatológica. Ensaio de teologia fundamental pósmoderna. São Paulo: Realizações, 2011.

BENTO XVI. Carta Encíclica Spe salvi. Sobre a Esperança Cristã, São Paulo: Paulinas, 2009.

SCHÖKEL, Luís Alonso. Bíblia do Peregrino, São Paulo: Paulus, 2006.

COMISSÃO EPISCOPAL PASTORAL PARA A ANIMAÇÃO BÍBLICOCATEQUÉTICO, Itinerário Catequético. Iniciação à vida cristã - um processo de inspiração catecumenal, Brasília: CNBB, 2017.

CONSELHO EPISCOPAL LATINO-AMERICANO, Documento de Aparecida. Texto Conclusivo da V Conferência Geral do Episcopado Latino-Americano e do Caribe. São Paulo: Paulus, 2007.

KLEIN, Willian W. BLOMBERG, Craig L. HUBBARD, Robert Jr., Introdução à interpretação bíblica, Rio de Janeiro: Thomas Nelson Brasil, 2017.

PAPA FRANCISCO. Exortação apostólica Evangelii Gaudium. A Alegria do Evangelho. Brasília: CNBB, 2013. 
PUPPI, Ubaldo. "Uma teoria da cultura" (Resenha). In: Trans /Form /Ação. Disponível em: $<$ https://www.scielo.br/scielo.php?script=sci arttext\&pid=So101$31731974000100014>$ Acesso em 03/07/2020.

RATZINGER, Joseph. Introdução ao Cristianismo. Preleções sobre o Símbolo Apostólico. Com um novo ensaio introdutório. São Paulo: Loyola, 2005.

RICOEUR, Paul. Hermenêutica filosófica e hermenêutica bíblica. In: Do texto à ação: ensaios de hermenêutica II. Portugal: Porto, 1989.

SOMAIN, René. "Religiões no Brasil". In: Confins. Revista Franco-Brasileira de Geografia. Número $15 . \quad$ Disponível em: $<$ https://journals.openedition.org/confins/7785?lang=pt $>\quad$ Acesso em 01/07/2020.

SOU CATEQUISTA. Documentos sobre a catequese no Brasil. Disponível em: $<$ https://soucatequista.com.br/documentos-sobre-a-catequese-da-igreja-nobrasil.html > Acesso em 02/07/2020.

SUSIN Luiz Carlos, O "calcanhar de Aquiles" da iniciação à vida cristã. In: Revista Eclesiástica Brasileira (REB), vol. 79, n. 312 (Jan./Abr.) 2019, p.34-59.

Recebido em: 04/08/2020. Aprovado em: 13/08/2020. Publicado em: 15/08/2020. 